\title{
An experimental investigation of vibration characteristics of compression ignition engine running with neem methyl ester
}

\author{
Madhava Varma B. ${ }^{1}$, Ravi Kumar N. ${ }^{1}$ and Prasanthi G. ${ }^{2}$ \\ ${ }^{1}$ Department of Mechanical Engineering, MVGR College of Engineering, \\ Chintalavalasa, Vizianagaram, Andhra Pradesh, India, 535005 \\ Email: madhavvarma1541@gmail.com \\ Phone: +91-9866142339 \\ ${ }^{2}$ Department of Mechanical Engineering, JNTUA College of Engineering, \\ Anantapuramu, Andhra Pradesh, India, 515002
}

\begin{abstract}
Reduction of fossil fuel reserves, environmental deterioration, global warming, and rigorous emission norms have necessitated the need for alternate fuel such as biodiesels. Diesel engines produce a higher vibration which leads to a reduced engine life span. In the present study, the vibration of a compression ignition engine has been measured for both diesel and Neem methyl ester. The experiments were carried out at $0 \%, 25 \%, 50 \%$, $75 \%$, and $100 \%$ load when the engine runs at a constant speed of $1500 \mathrm{rpm}$ and with a compression ratio of 16 . Triaxial accelerometer is used for measuring engine vibration along vertical, lateral, and longitudinal directions. Data acquisition and analysis are obtained by NI LabVIEW. It has been observed that an engine running with NME produces lower combustion induced vibration acceleration compared to diesel fuel. It is also noticed that higher peak amplitudes are observed at the frequency of $25 \mathrm{~Hz}$ for both diesel and NME, within the range of $0-100 \mathrm{~Hz}$ and along three directions. Within the range of 100-3000 Hz, the highest peak amplitudes are observed for engine running with diesel compared to neem methyl ester. At a $100 \%$ load, the change in vibration amplitude is $64.94 \%, 86.41 \%$, and $17 \%$ along vertical, lateral, and longitudinal directions when fuel is changed from NME to diesel. Combustion characteristics such as maximum cylinder pressure, heat release rate, and rate of pressure rise are also measured for both diesel and NME in order to find the relationship between combustion and vibration. At full load conditions, the maximum combustion pressure and maximum rate of pressure rise are increased by $2.1 \%$ and $8.33 \%$ with pure diesel compared to neem methyl ester. The experimental work suggests that neem methyl ester can be directly used in diesel engines in view of a lesser engine vibration and higher engine life.
\end{abstract}

Keywords: Biodiesel; peak amplitude; triaxial accelerometer; combustion; vibration analysis.

\section{INTRODUCTION}

Diesel engines produce a higher vibration and hence sound; which causes discomfort to the occupants of automobiles [1,2]. They also discharge considerable amounts of pollutants into the atmosphere, creating environmental-related problems [3]. The combustion process in the engine cylinder is also one source of engine vibration. Higher vibrations are observed in the engines with high compression ratios $[4,5]$. The engine 
block vibration looks like a very complex signal in which various sources can be determined, as every moving component or physical process associated in the operation of the engine initiates a vibration signal. Various sources impart to the vibration and acoustic emissions from CI engines such as mechanical, aerodynamic, thermal, and combustion induced vibration and noise [6]. The combustion induced vibrations correlated with the exothermic mixture burning which generate a spectrum of pressure waves moving in all directions inside the combustion chamber hitting the piston, the cylinder walls, and cylinder head leading to the vibration [5]. The vibration signals from the cylinder head are normally non-stationary signals and they are generally analysed with time domain and frequency domain analysis [7]. The combustion process inside the engine cylinder can be studied by means of a direct measurement with a combustion pressure transducer which is expensive, unreliable, and difficult for installation in the hostile engine environment [8-11] Hence, non-intrusive measuring techniques are put into practice to study the combustion process inside the engine cylinder as they retain the advantage of being less expensive; durable and reliable; and easy to use [12-15].

It is also observed that a vibration induced due to mechanical components is less evident than that of a vibration due to combustion process. Non-intrusive sensors are made up of a piezoelectric material which works on the principle of the piezoelectric effect [16]. Arasaratnam et al. [17] concluded that the faulty engine condition can be distinguished from a normal engine using spectral and vibration analysis. In cylinder pressure, fluctuations mostly control the engine vibration signals and with the increase of load and engine speed, the engine block vibration accelerations rise [18]. It is noticed that the accelerometer located in a vertical direction is the most sensitive to the combustion process and it is also realized that waveforms of fired engine are moving away from that of waveforms of motored engine [19]. Biodiesel has been recognized as one of the most economically feasible renewable fuels in the world; which has attracted much attention in the last few years [20]. Biodiesels are mono alkyl esters of long chain fatty acids produced from vegetable oils, animal fats, and waste restaurant grease [21-27]; They are more significant among different alternate fuels as they are renewable, non- toxic, sulphur- free, biodegradable, oxygenated, and environmentally friendly [28-34]. On the other hand, their disadvantages are higher viscosity and pour point, lower calorific value. and volatility [35]. Biodiesels are produced by transesterification of raw vegetable oil or fats in which they are made to react with alcohol in the presence of a catalyst [36-39] to produce alkyl esters and glycerol [40, 41].

It is reported that the total (net) value of acceleration amplitude is significantly affected by biofuel and its blends, which is due to the change in gas pressure inside the cylinder chamber. It is also noticed that the vibration of pure biodiesel is more than pure diesel [42]. Barelli et al. [43] diagnosed the internal combustion engine through vibration and acoustic pressure using non-intrusive measurements, for different values of the engine load. It is observed that the most part of the signal energy is in the frequency range within $2000 \mathrm{~Hz}$, and confirms that mechanical solicitations occur mostly at low frequencies. Goldwine et al. [44] studied the relationship between vibration signature and combustion process. This study concluded that the peak amplitude of vibration is greatly affected by rate of pressure rise in the engine. Chiatti et al. [45] highlighted that the vibration trace is very sensitive to the initial ignition of the fuel injected which causes the pressure increase and then the block vibration.

Schaberg et al. [46] investigated that higher modes of axial vibrations are prominent in larger engines whereas horizontal and vertical vibrations are lower and has higher high frequency content. A major drop of $13.7 \%$ in RMS value of vibration 
acceleration is observed with $\mathrm{B} 50$ at an engine load of $0.86 \mathrm{MPa}$ compared to baseline diesel [47]. Chiatti et al. [48] utilized a vibration signal to compute the angular position at which $50 \%$ of mass is burned inside the cylinder. Yong Cheng et al. [49] concluded that a vibration velocity below $2000 \mathrm{~Hz}$ is highly correlated to the combustion process. The objective of the present work is to study the effects of load and fuel on engine vibration along three mutually perpendicular directions which are vertical, lateral, and longitudinal directions. The time and frequency domain data of an engine block vibration signal allowed the study of a combustion induced vibration of engine fuelled with diesel and NME at various loads. The tests were performed in a VCR diesel engine by varying loads at a constant speed of $1500 \mathrm{rpm}$.

\section{EXPERIMENTAL METHODOLOGY}

\section{Experimental Setup}

In this study, the vibration of a four-stroke VCR diesel engine is measured by mounting the triaxial accelerometer on top of the cylinder head. Vibration data is acquired for engine running with diesel and NME by varying the load from zero to a maximum of 12 $\mathrm{kg}$, when it is running at a constant speed of $1500 \mathrm{rpm}$. The VCR engine is set to a compression ratio of 16. The engine specifications are given in Table 1. The engine setup and position of the triaxial accelerometer are shown in Figure 1.

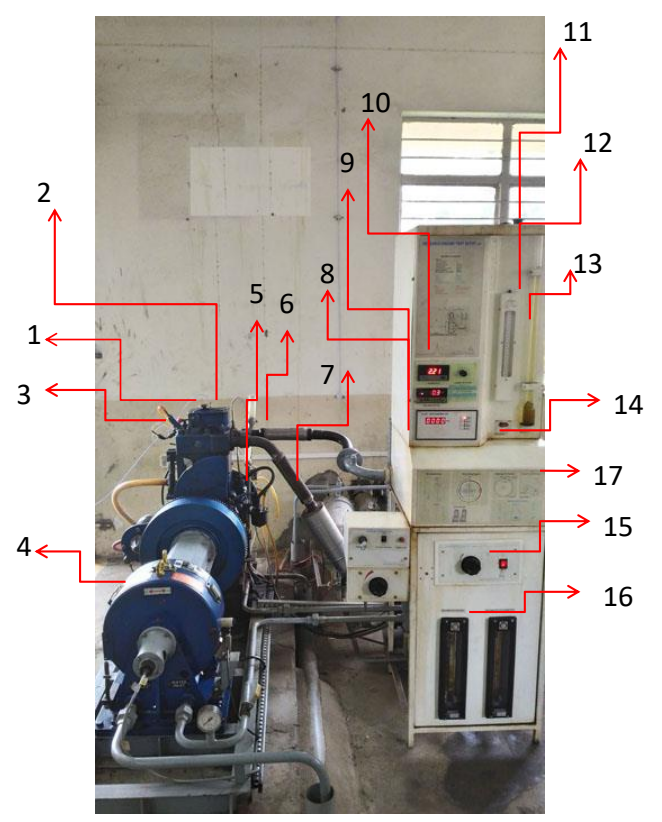

1. Triaxial accelerometer

2. Engine head

3. Fuel injector

4. Eddy current dynamometer

5. Fuel pump

6. Inlet manifold

7. Exhaust manifold

8. Piezo powering unit

9. Load indicator

10. Digital voltmeter

11. Fuel tank

12. U-tube manometer

13. Fuel pipe

14. Fuel cock

15. Dynamometer loading unit

16. Rotameters

17. Data acquisition system

Figure 1. Engine setup.

\section{Production of Neem Methyl Ester}

Raw neem oil is purchased from the local market and converted into neem methyl ester by transesterification process. This process is basically used to reduce the viscosity of the raw neem oil. In this process, large branched triglyceride molecules of vegetable oils are transformed into smaller straight chain molecules; which are required in CI engines [50]. Properties of diesel and NME are determined as per ASTM standards which are given in Table 2. The calorific value and kinematic viscosity are measured using Bomb 
Calorimeter and Redwood viscometer 1. The flash point and fire point are measured using Pensky-Martens closed cup tester. The cloud point and pour point are measured using cloud and pour point apparatus. The density is measured using digital density meter.

\section{Data Acquisition Procedure}

In acquiring vibration signals of the engine, a triaxial accelerometer with a sensitivity of $5 \mathrm{mV} / \mathrm{g}$ is used. It is used to measure the vibration acceleration of the engine head along vertical, lateral, and longitudinal directions. The specifications of a triaxial accelerometer are shown in Table 3. The triaxial accelerometer is mounted on the engine head using loctite adhesive. It is also connected to a NI 9234 (A/D converter) data acquisition card as shown in Figure 2. NI 9234 has four BNC connectors that provide connections to four simultaneously sampled analog input channels with an input range of $\pm 5 \mathrm{~V}$. Each channel has a BNC connector to which a signal source can be connected. Three input channels of the triaxial accelerometer are connected to AI $0, \mathrm{AI} 1$, and AI 2 of the A/D converter. The vibration measurement setup is shown in Figure 2. Finally, the collected data are transferred by a cable to the USB port of a laptop for recording. The data acquisition duration for each test was $60 \mathrm{~s}$. The NI LabVIEW software is used to write the programme for measurement of the vibration. The time waves and frequency spectrums are used for analysing the engine vibration. As time waves cannot give the information of different sources of vibration, they are converted into frequency spectrums using the fast Fourier transform. The time domain signals are taken at the mentioned sampling frequency of $51.2 \mathrm{kHz}$ for 12.5 complete consecutive combustion cycles. A piezoelectric pressure sensor with a sensitivity of $1 \mathrm{mV} / \mathrm{PSI}$ and range of 5000PSI are used for combustion pressure measurement.

Table 1. Specifications of engine.

\begin{tabular}{ll}
\hline Make & Kirloskar \\
\hline Engine type & Single cylinder, 4 stroke, VCR, water \\
Stroke & $110 \mathrm{~mm}$ \\
Bore & $87.5 \mathrm{~mm}$ \\
Speed & $1500 \mathrm{rpm}$ \\
Range of compression ratio & $12-18$ \\
Injection timing & $23 \mathrm{deg}$ BTDC \\
Injection pressure & $200 \mathrm{bar}$ \\
\hline
\end{tabular}

Table 2. Properties of diesel and NME.

\begin{tabular}{|c|c|c|c|}
\hline Property & Method & Diesel & NME \\
\hline Calorific value $(\mathrm{kJ} / \mathrm{kg})$ & D 240 & 42,500 & 38,500 \\
\hline Kinematic Viscosity $(\mathrm{cSt}) @ 40^{\circ} \mathrm{C}$ & D 445 & 2.4 & 4.4 \\
\hline Density $\left(\mathrm{Kg} / \mathrm{m}^{3}\right)$ & D 4052 & 835.6 & 875.8 \\
\hline Flash point $\left({ }^{\circ} \mathrm{C}\right)$ & D 93 & 56 & 183 \\
\hline Cloud Point $\left({ }^{\circ} \mathrm{C}\right)$ & D 2500 & -12 & 9 \\
\hline Pour point $\left({ }^{\circ} \mathrm{C}\right)$ & D 97 & -16 & 2 \\
\hline Fire point $\left({ }^{\circ} \mathrm{C}\right)$ & D 93 & 58 & 205 \\
\hline
\end{tabular}


Table 3. The specifications of triaxial accelerometer.

\begin{tabular}{lc}
\hline \multicolumn{1}{c}{ Product } & PCB Triaxial accelerometer \\
\hline Sensitivity $( \pm 20 \%)$ & $5 \mathrm{~m} \mathrm{~V} / \mathrm{g}$ \\
Measurement range & $\pm 1000 \mathrm{~g} \mathrm{pk}$ \\
Frequency range $( \pm 5 \%) \mathrm{Y}$ or $\mathrm{Z}$ axis & 2 to $8000 \mathrm{~Hz}$ \\
Frequency range $( \pm 5 \%) \mathrm{X}$ axis & 2 to $5000 \mathrm{~Hz}$ \\
Resonant frequency & $\geq 50 \mathrm{kHz}$ \\
Weight (without cable) & $1 \mathrm{~g}$ \\
\hline
\end{tabular}

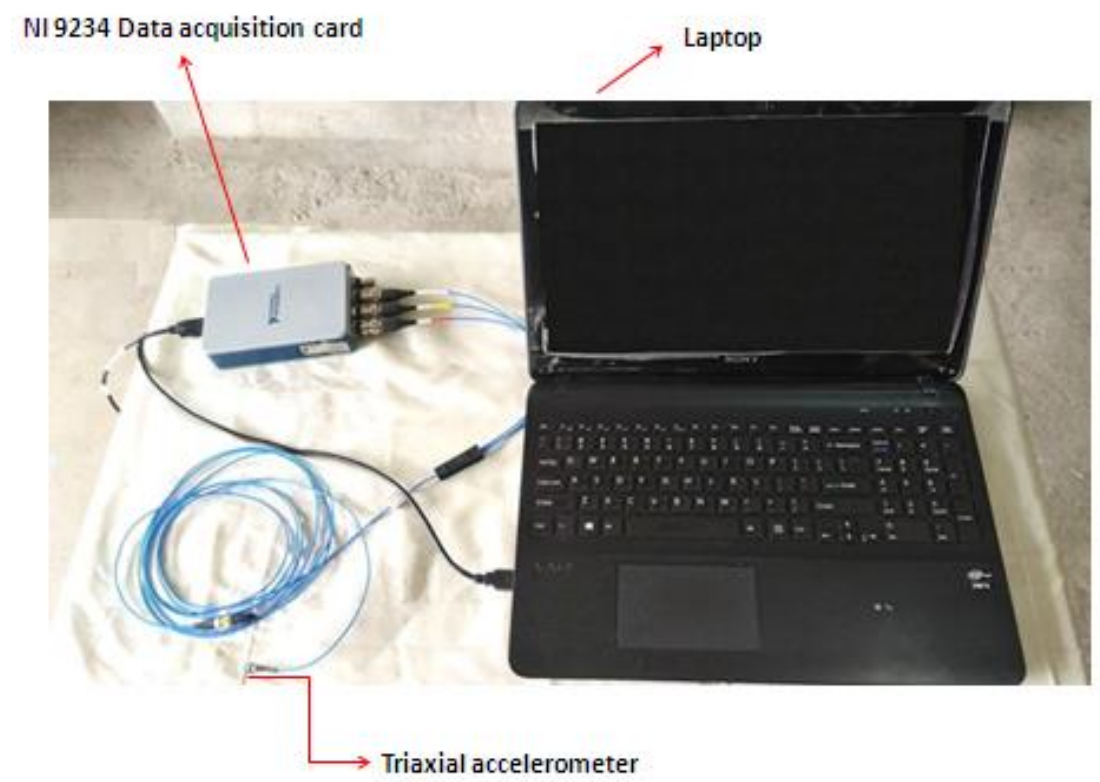

Figure 2. Vibration measurement setup.

\section{RESULTS AND DISCUSSION}

\section{Engine Vibration in Vertical Direction}

Figure 3 shows the super imposed time waves of an engine vibration, in vertical direction, when it is fuelled with diesel and NME, at a maximum load of $12 \mathrm{~kg}$. It is realized that the overall vibration varies between $-3500 \mathrm{~m} / \mathrm{s}^{2}$ to $4000 \mathrm{~m} / \mathrm{s}^{2}$ for both diesel and NME. The overall vibration consists of different sources of vibrations, therefore it is not a reliable parameter to judge the effects of fuel and hence the combustion process, on engine vibration. The peaks (maximum amplitudes) of the time domain signals indicate the peak pressures in the cylinder during the combustion process. Figure 4(a) depicts super imposed frequency spectrums within the range of $0-100 \mathrm{~Hz}$, at a maximum load of $12 \mathrm{~kg}$ for engine fuelled with diesel and NME. The first peak is observed at the frequency of $12.5 \mathrm{~Hz}$, which indicates the frequency of combustion [17], and the harmonics are observed at frequencies of $25 \mathrm{~Hz}, 37.5 \mathrm{~Hz}, 50 \mathrm{~Hz}$, and so on in the multiples of $12.5 \mathrm{~Hz}$. The highest peak amplitude is observed at the frequency of $25 \mathrm{~Hz}$ (engine speed), for engine fuelled with diesel and NME and they are $1.59 \mathrm{~m} / \mathrm{s}^{2}$ and $1.61 \mathrm{~m} / \mathrm{s}^{2}$ at maximum load as shown in Figure 4(a). 
The high amplitude frequencies below $200 \mathrm{~Hz}$ are probably due to spurious sources and cannot be related to any combustion phenomena [9]. It is proven that high values of coherence are exhibited between the vibration signals in vertical direction with the in-cylinder pressure in the frequency band of $500 \mathrm{~Hz}-1100 \mathrm{~Hz}$ [17]. After $100 \mathrm{~Hz}$, the highest peak amplitude is observed around $676 \mathrm{~Hz}$ with an amplitude of $4.47 \mathrm{~m} / \mathrm{s}^{2}$ in the case of engine operated with diesel, whereas it is $2.71 \mathrm{~m} / \mathrm{s}^{2}$ at $695 \mathrm{~Hz}$, for engine operated with NME as shown in Figure 4(b). It is also realized that the high frequency vibrations are dominating for engine fuelled with diesel compared to NME and it may be due to lower cetane number of diesel when compared to NME. The ignition quality of a fuel is usually characterized by its cetane number and a higher cetane number generally means a shorter ignition delay [51].

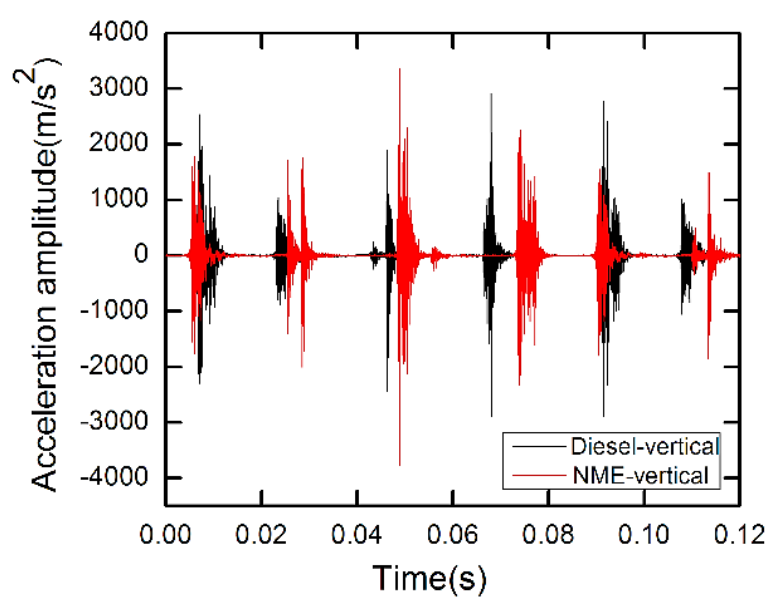

Figure 3. Timewaves in the vertical direction for engine running with diesel and $\mathrm{NME}$ at a maximum load of $12 \mathrm{~kg}$.

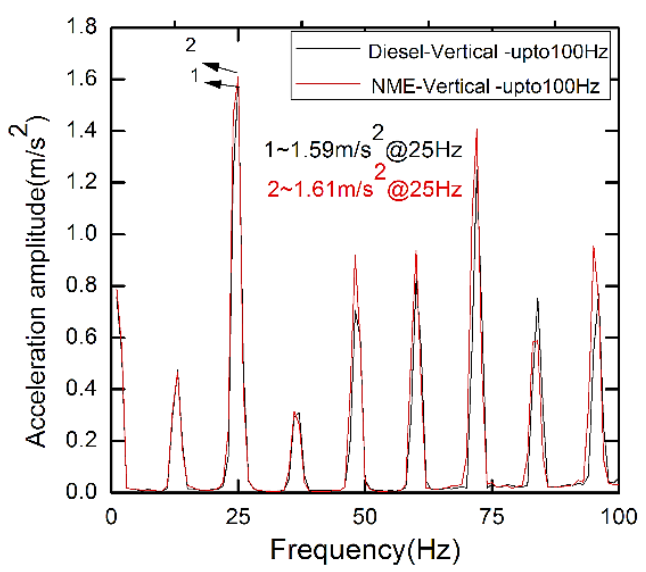

(a)

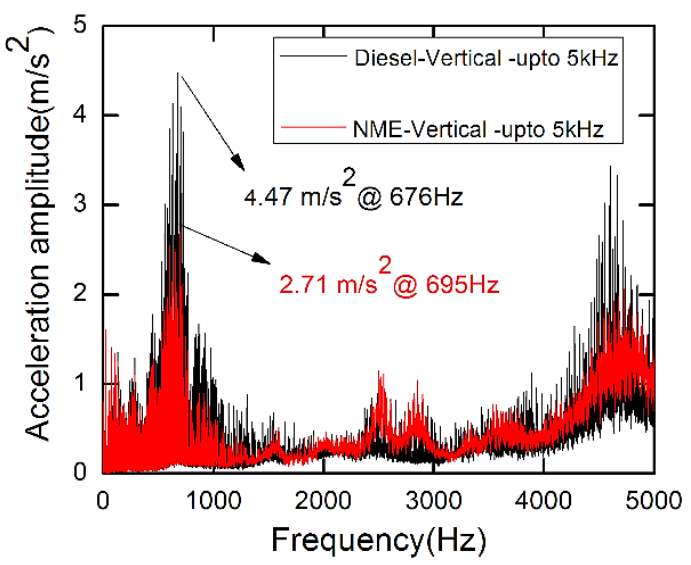

(b)

Figure 4. Frequency spectrums in vertical direction for engine running with diesel and $\mathrm{NME}$ at a maximum load of $12 \mathrm{~kg}$ (a) up to $100 \mathrm{~Hz}$ (b) up to $5 \mathrm{kHz}$.

Figure 5 shows the peak acceleration amplitudes at various loads, in the frequency range of $0-100 \mathrm{~Hz}$, in vertical direction for engine running with diesel and NME. It is realized that at any load, the highest peak is observed at the frequency of $25 \mathrm{~Hz}$ for engine running with both diesel and NME. It amounts to about $1.42 \mathrm{~m} / \mathrm{s}^{2}, 1.54 \mathrm{~m} / \mathrm{s}^{2}, 1.65 \mathrm{~m} / \mathrm{s}^{2}, 1.68 \mathrm{~m} / \mathrm{s}^{2}$, 
and $1.59 \mathrm{~m} / \mathrm{s}^{2}$ for engine running with diesel from zero to maximum load and the same amounts to $1.56 \mathrm{~m} / \mathrm{s}^{2}, 1.66 \mathrm{~m} / \mathrm{s}^{2}, 1.73 \mathrm{~m} / \mathrm{s}^{2}, 1.68 \mathrm{~m} / \mathrm{s}^{2}$, and $1.61 \mathrm{~m} / \mathrm{s}^{2}$ for engine running with NME. The change in peak acceleration amplitude is $11.97 \%$ and $3.2 \%$ in the case of diesel and NME when load is changed from zero to maximum of $12 \mathrm{~kg}$. The second highest peak amplitude is observed at the frequency of $75 \mathrm{~Hz}$ for both diesel and NME and it is maximum at full load for both diesel and NME. It is noticed that in the absence of load, peak amplitudes are lesser as it may be due to less fuel consumption and less pressure developed inside the cylinder. The peak acceleration amplitudes are higher at $50 \%$ and $75 \%$ load for both diesel and NME. At all other harmonic frequencies, diesel and NME showed higher amplitudes at full load.

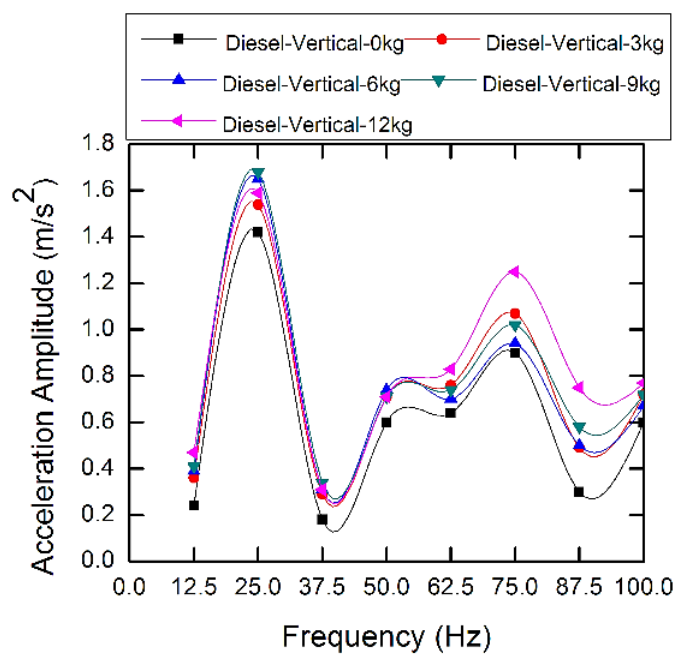

(a)

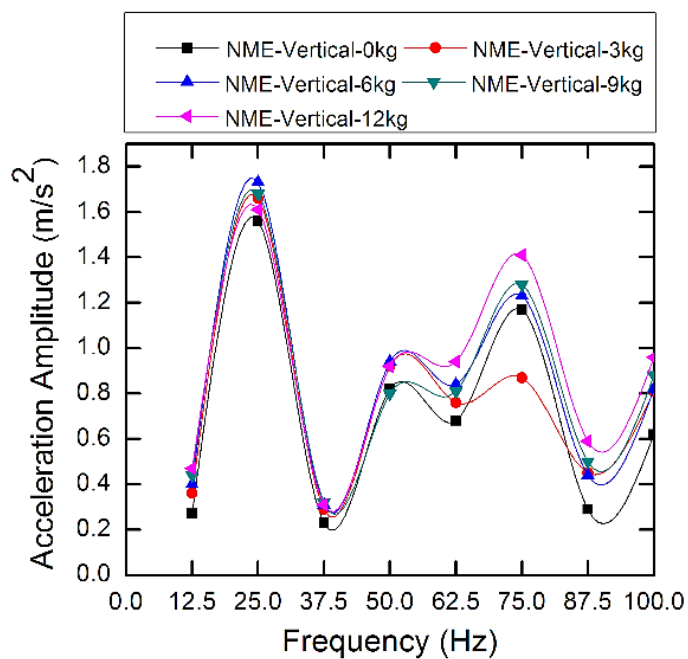

(b)

Figure 5. Peak accelerations in vertical direction for (a) diesel (b) NME.

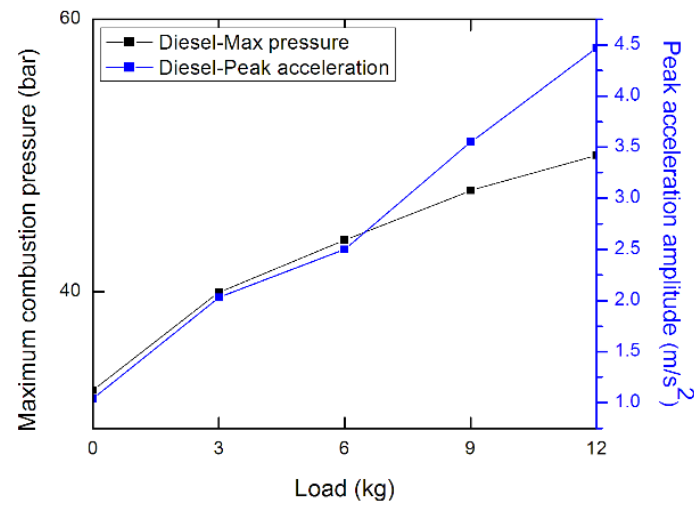

(a)

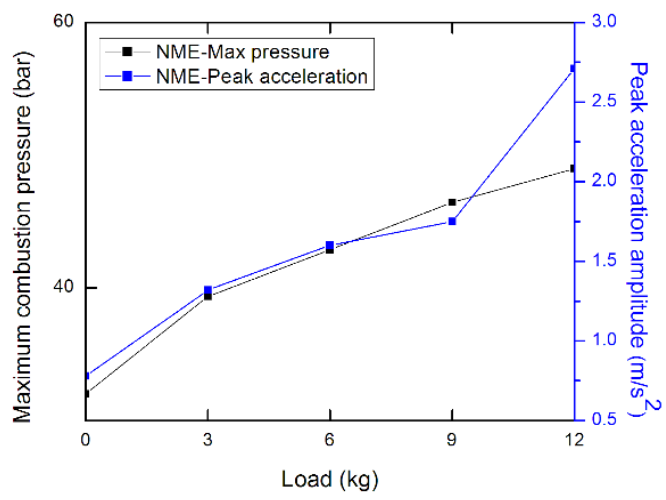

(b)

Figure 6. Maximum combustion pressure and maximum peak acceleration amplitude of vibration in vertical direction with respect to load for engine running with (a) diesel (b) NME.

Figure 6 shows maximum combustion pressure and maximum peak acceleration amplitude of vibration in vertical direction in the range of $100 \mathrm{~Hz}-3000 \mathrm{~Hz}$, with respect to load, for engine running with diesel and NME. It is noticed that the maximum 
combustion pressures are higher for engine fueled with diesel compared to NME and it may be due to the slightly higher delay period of diesel over NME, which is due to lower cetane number of diesel over biodiesel [52]. The maximum combustion pressure, from no load to full load, changes from 32.8 bar to 50.02 bar when the engine is operated with diesel whereas it changes from 32 bar to 49 bar when engine is operated with NME.

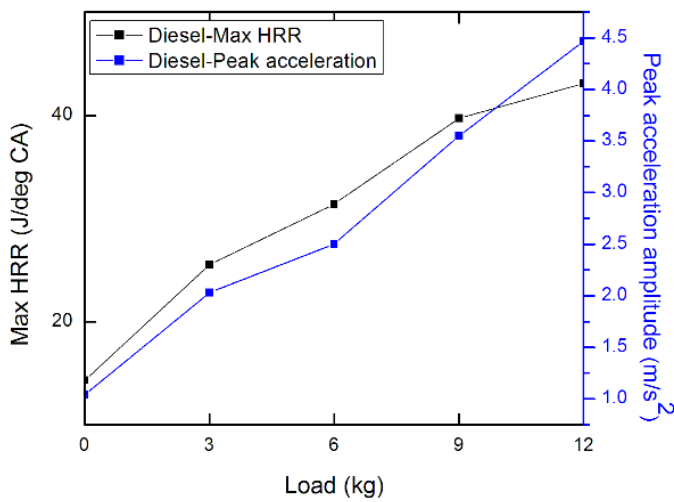

(a)

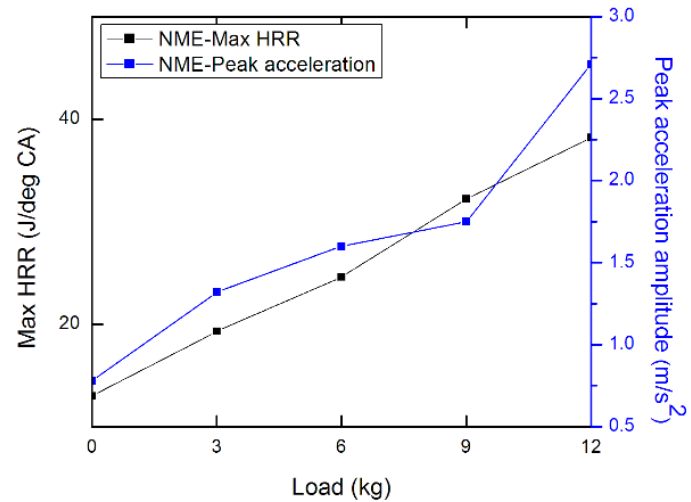

(b)

Figure 7. Maximum heat release rate and maximum peak acceleration amplitude of vibration in vertical direction with respect to load for engine running with (a) diesel (b)

NME.

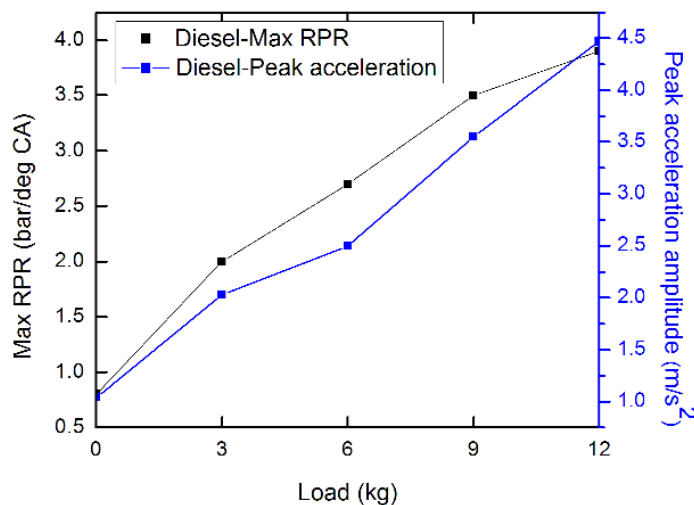

(a)

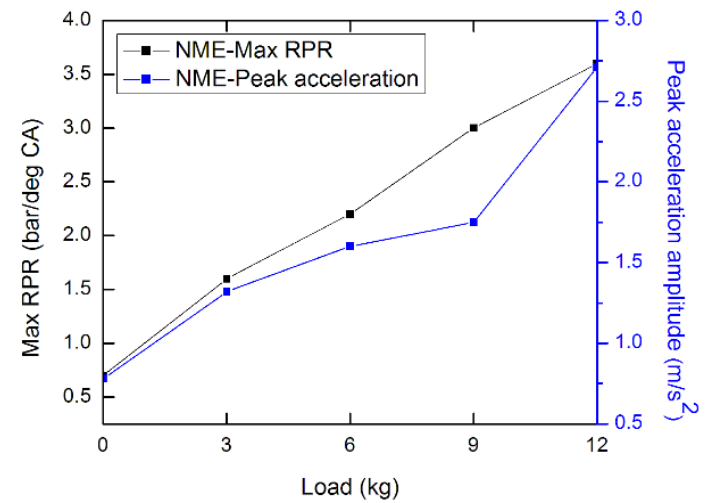

(b)

Figure 8. Maximum rate of pressure rise and maximum peak acceleration amplitude of vibration in vertical direction with respect to load for engine running with (a) diesel (b)

NME

Figure 7 shows the maximum heat release rate and maximum peak acceleration amplitude of vibration in vertical direction in the range of $100 \mathrm{~Hz}-3000 \mathrm{~Hz}$, with respect to load, for engine running with diesel and NME. The maximum heat release rate, from no load to full load, changes from $14.3 \mathrm{~J} / \mathrm{deg} C A$ to $43.1 \mathrm{~J} / \mathrm{deg} C A$ when engine is operated with diesel whereas it changes from $13 \mathrm{~J} / \mathrm{deg} \mathrm{CA}$ to $38.2 \mathrm{~J} / \mathrm{deg} \mathrm{CA}$ when the engine is operated with NME. Figure 8 shows the maximum rate of pressure rise and maximum peak acceleration amplitude of vibration in vertical direction in the range of $100 \mathrm{~Hz}-3000$ $\mathrm{Hz}$, with respect to load, for engine running with diesel and NME. The maximum rate of pressure rise, from no load to full load, changes from $0.8 \mathrm{bar} / \mathrm{deg} \mathrm{CA}$ to $3.9 \mathrm{bar} / \mathrm{deg} \mathrm{CA}$ when engine is operated with diesel whereas it changes from 0.7 bar /deg CA to 3.6 bar 
/deg CA when engine is operated with NME. The maximum peak accelration, in vertical direction, changes from $1.04 \mathrm{~m} / \mathrm{s}^{2}$ to $4.47 \mathrm{~m} / \mathrm{s}^{2}$ when engine is operated with diesel whereas it changes from $0.78 \mathrm{~m} / \mathrm{s}^{2}$ to $2.71 \mathrm{~m} / \mathrm{s}^{2}$ when engine is operated with NME. At full load, the maximum combustion pressure and maximum rate of pressure rise increased by $2.1 \%$ and $8.33 \%$ with pure diesel compared to neem methyl ester. It is noticed that more correlations are observed between the maximum rate of pressure rise and peak acceleration amplitude of vibration. H.G. How et al. [47] also noticed that a variation of vibration accelerations are very similar with the variation in peak pressure rise rate.

\section{Engine Vibration in Lateral Direction}

Figure 9 shows super imposed time waves of an engine fuelled with diesel and NME at a maximum load of $12 \mathrm{~kg}$, in lateral direction. It is realized that the overall vibration varies between $-1500 \mathrm{~m} / \mathrm{s}^{2}$ to $1500 \mathrm{~m} / \mathrm{s}^{2}$ for both diesel and NME. The time wave represents the overall vibration of engine, which is due to different sources such as combustion and mechanical forces of the engine. These forces occur over a wide frequency range and are passed to the external surface of the engine with different amplitudes of vibration [1]. Hence, time waves may not be used for analysing the effects of fuel on combustion induced vibration. Figure 10 depicts super imposed frequency spectrums at a maximum load of $12 \mathrm{~kg}$ for engine fuelled with diesel and NME, in lateral direction. In the lateral direction also, the first peak is observed at the frequency of $12.5 \mathrm{~Hz}$ and the remaining peaks are found at the frequencies of multiple $12.5 \mathrm{~Hz}$. In the lateral direction, the highest peak acceleration amplitudes are located at the frequency of $25 \mathrm{~Hz}$ for both diesel and NME and they are $9.4 \mathrm{~m} / \mathrm{s}^{2}$ and $9.42 \mathrm{~m} / \mathrm{s}^{2}$ at maximum load as shown in Figure 10(a). These high amplitudes are probably due to spurious sources and cannot be associated to any combustion phenomena as the energy of combustion is prevailing in the high frequency band of $1500-3000 \mathrm{~Hz}$ [9]. After $100 \mathrm{~Hz}$, the highest peak is observed between $2500 \mathrm{~Hz}$ to $2700 \mathrm{~Hz}$ for both diesel and NME and it is higher for diesel due to its lower cetane number compared to NME. This highest peak amplitude is observed around 2548 $\mathrm{Hz}$ with an amplitude of $3.84 \mathrm{~m} / \mathrm{s}^{2}$ in the case of engine operated with diesel, whereas it is $2.06 \mathrm{~m} / \mathrm{s}^{2}$ at $2500 \mathrm{~Hz}$, for engine operated with NME as shown in Figure 10(b).

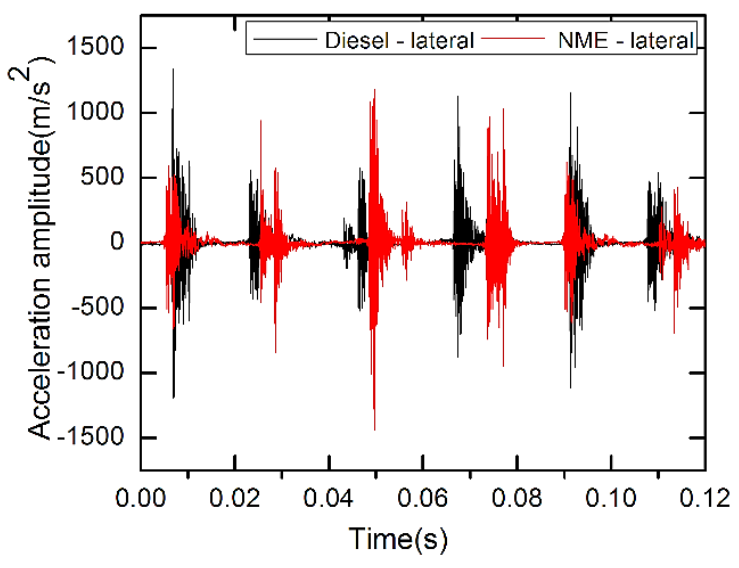

Figure 9. Time waves in lateral direction for engine running with diesel and NME at a maximum load of $12 \mathrm{~kg}$.

Figure 11 shows peak accelerations in the lateral direction, from zero to maximum load for the two vibration signals when engine is running with diesel and NME. At $25 \mathrm{~Hz}$ 
frequency, peak amplitudes occur at $7.82 \mathrm{~m} / \mathrm{s}^{2}, 8.62 \mathrm{~m} / \mathrm{s}^{2}, 9.57 \mathrm{~m} / \mathrm{s}^{2}, 9.76 \mathrm{~m} / \mathrm{s}^{2}$, and 9.4 $\mathrm{m} / \mathrm{s}^{2}$ for engine running with diesel from zero to maximum load and the same value occuring at $8.83 \mathrm{~m} / \mathrm{s}^{2}, 9.28 \mathrm{~m} / \mathrm{s}^{2}, 9.83 \mathrm{~m} / \mathrm{s}^{2}, 9.66 \mathrm{~m} / \mathrm{s}^{2}$, and $9.42 \mathrm{~m} / \mathrm{s}^{2}$ for engine running with NME. The change in peak acceleration amplitude is $20.2 \%$ and $6.7 \%$ in the case of diesel and NME when load is changed from zero to maximum of $12 \mathrm{~kg}$. In the lateral direction also, peak amplitudes are observed to be lesser at no load as it is observed in the vertical direction. Similar to vertical direction, peak amplitudes are higher at $50 \%$ and $75 \%$ load for both diesel and NME. At other harmonic frequencies, diesel and NME showed higher amplitudes at full load. After $25 \mathrm{~Hz}$, next highest peaks are obtained at the frequencies of $50 \mathrm{~Hz}, 75 \mathrm{~Hz}$, and $100 \mathrm{~Hz}$; which are multiples of $25 \mathrm{~Hz}$.

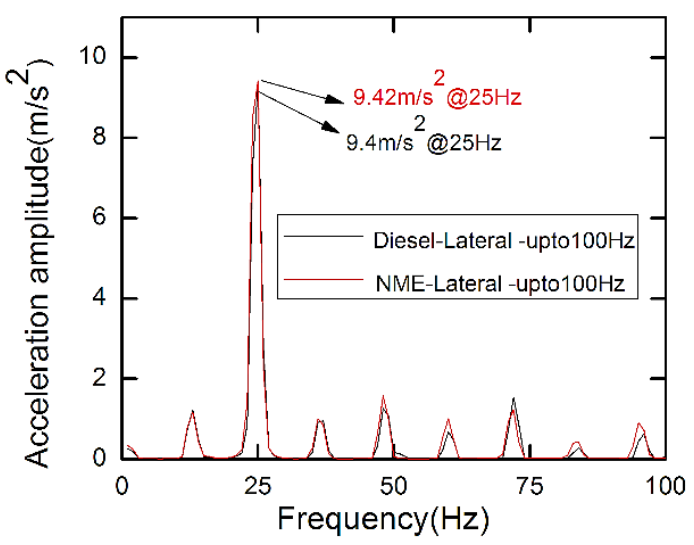

(a)

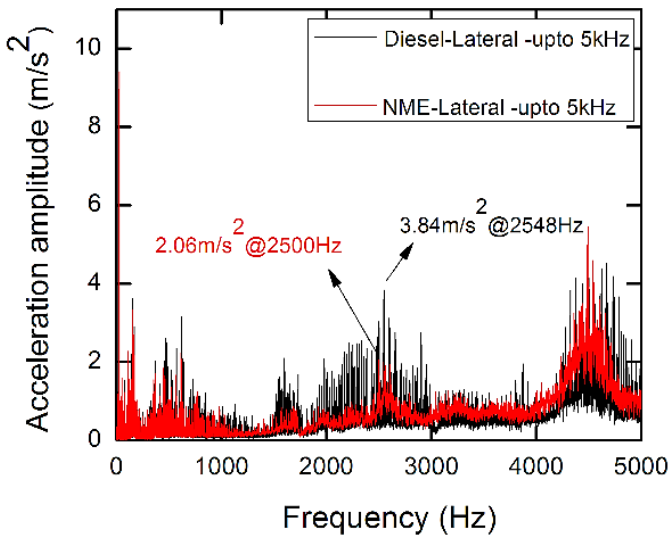

(b)

Figure 10. Frequency spectrums in lateral direction for engine running with diesel and $\mathrm{NME}$ at a maximum load of $12 \mathrm{~kg}$ (a) up to $100 \mathrm{~Hz}$ (b) up to $5 \mathrm{kHz}$.

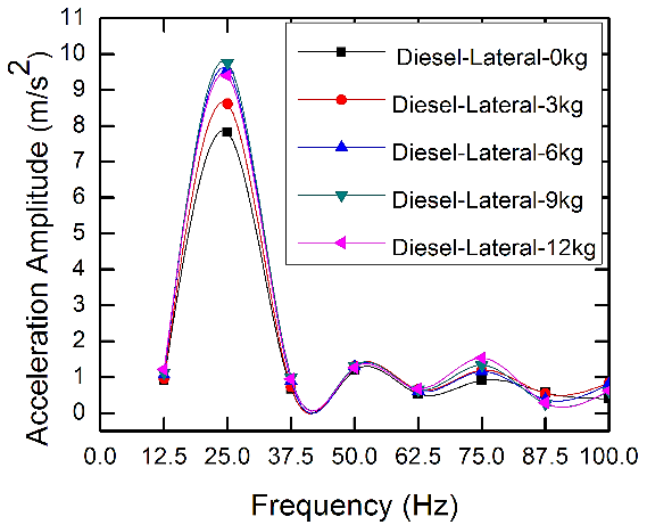

(a)

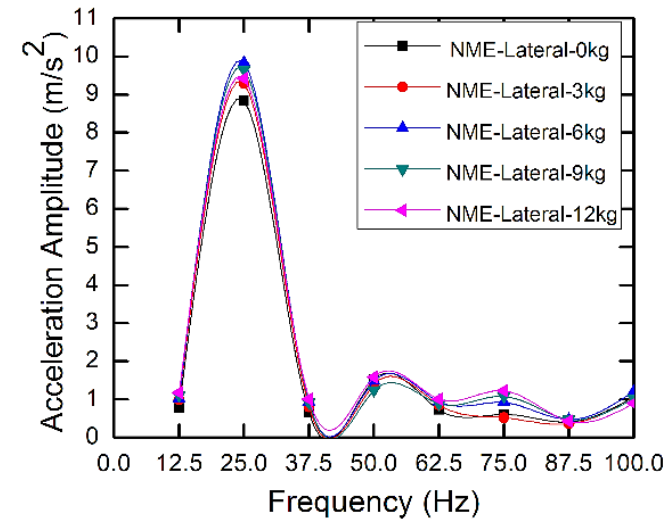

(b)

Figure 11. Peak accelerations in lateral direction for (a) diesel (b) NME.

\section{Engine Vibration in Longitudinal Direction}

Figure 12 shows the super imposed time waves of an engine fuelled with diesel and NME at a maximum load of $12 \mathrm{~kg}$, in longitudinal direction. It is realized that the overall vibration varies between $-3500 \mathrm{~m} / \mathrm{s}^{2}$ to $3000 \mathrm{~m} / \mathrm{s}^{2}$ for both diesel and NME. The maximum absolute vibration amplitudes are noticed as $3190 \mathrm{~m} / \mathrm{s}^{2}$ and $2255 \mathrm{~m} / \mathrm{s}^{2}$ in the case of engine fuelled with diesel and NME which are obtained as a result of combustion and mechanical 
induced vibration. Figure 13 depicts the super imposed frequency spectrums at a maximum load of $12 \mathrm{~kg}$ for engine fuelled with diesel and NME, in longitudinal direction. In this direction also, the first peak is observed at the frequency of $12.5 \mathrm{~Hz}$ and the remaining peaks are observed at frequencies of multiple $12.5 \mathrm{~Hz}$. After $100 \mathrm{~Hz}$, the highest peak is observed between $2500 \mathrm{~Hz}$ to $2800 \mathrm{~Hz}$ for both diesel and NME and it is higher for diesel compared to NME as shown in Figure 13(b). It may be due to a higher combustion induced vibration in the case of engine operated with diesel compared to NME which may be due to a lower cetane number of diesel over NME.

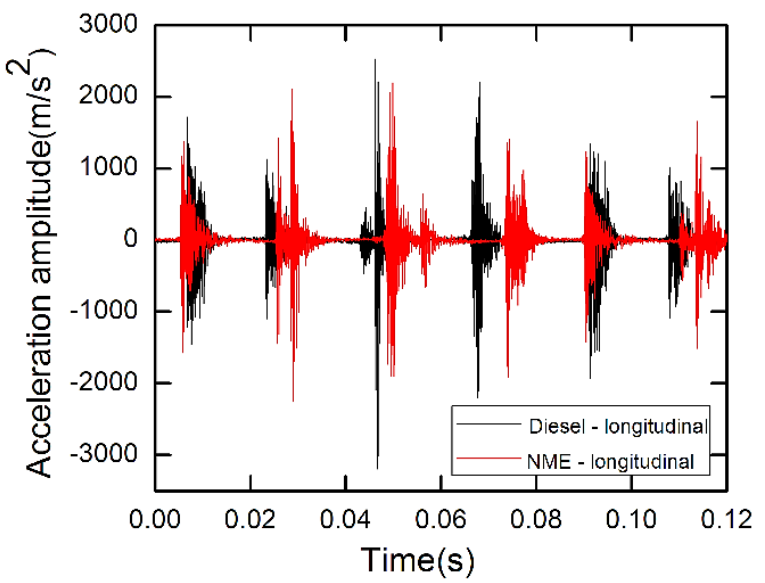

Figure 12. Time waves in longitudinal direction for engine running with diesel and $\mathrm{NME}$ at a maximum load of $12 \mathrm{~kg}$.

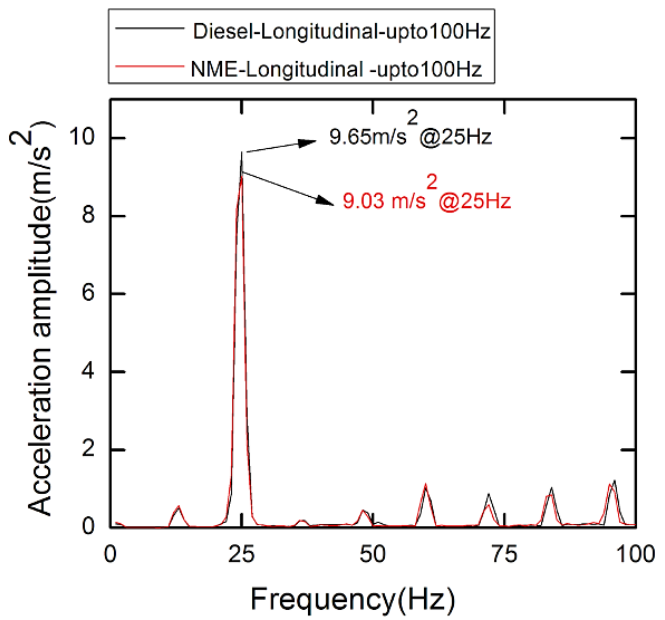

(a)

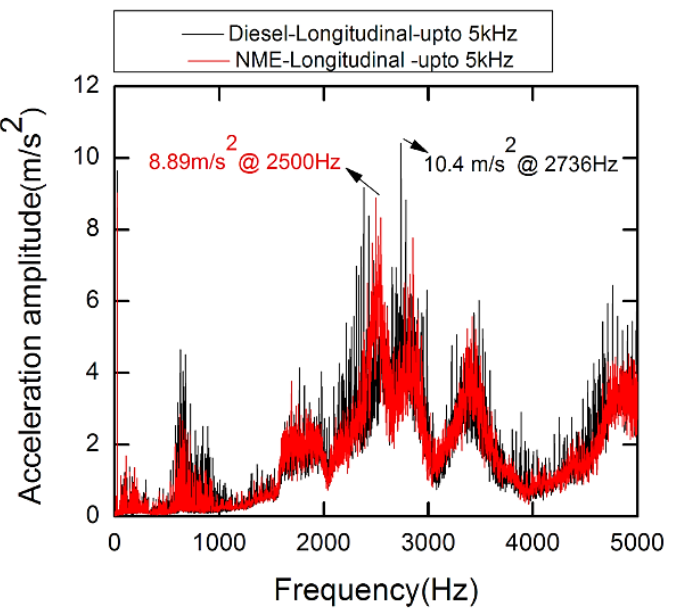

(b)

Figure 13. Frequency spectrums in longitudinal direction for engine running with diesel and $\mathrm{NME}$ at a maximum load of $12 \mathrm{~kg}$ (a) up to $100 \mathrm{~Hz}$ (b) up to $5 \mathrm{kHz}$. 


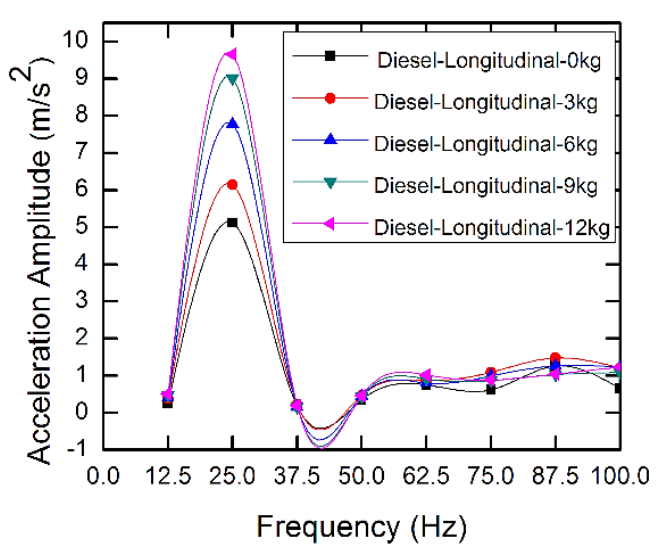

(a)

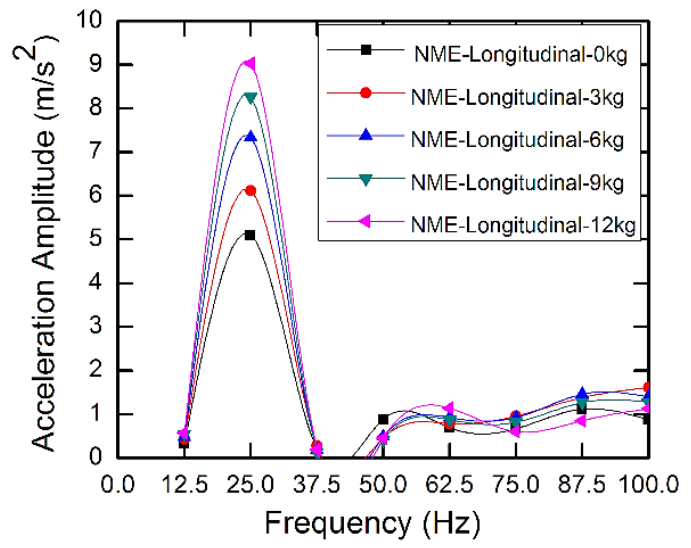

(b)

Figure 14. Peak accelerations in longitudinal direction for (a) diesel (b) NME.

Figure 14 shows the peak accelerations in longitudinal direction, from zero to maximum load for the two vibration signals when engine is running with diesel and NME. It is noticed that in longitudinal direction also, the highest peak amplitudes are observed at the frequency of $25 \mathrm{~Hz}$ for both diesel and NME. It occurs at $5.12 \mathrm{~m} / \mathrm{s}^{2}, 6.14 \mathrm{~m} / \mathrm{s}^{2}, 7.77$ $\mathrm{m} / \mathrm{s}^{2}, 9.01 \mathrm{~m} / \mathrm{s}^{2}$, and $9.65 \mathrm{~m} / \mathrm{s}^{2}$ for engine running with diesel from zero to maximum load and the same occurs at $5.1 \mathrm{~m} / \mathrm{s}^{2}, 6.12 \mathrm{~m} / \mathrm{s}^{2}, 7.34 \mathrm{~m} / \mathrm{s}^{2}, 8.26 \mathrm{~m} / \mathrm{s}^{2}$, and $9.03 \mathrm{~m} / \mathrm{s}^{2}$ for engine running with NME. The highest peak acceleration amplitudes are observed at a maximum load of $12 \mathrm{~kg}$. The change in peak acceleration amplitude is $88.5 \%$ and $77.05 \%$ in the case of diesel and NME when the load is changed from zero to the maximum of $12 \mathrm{~kg}$. It is noticed that, in longitudinal direction, engine vibration is significantly affected with respect to load for both diesel and NME. It may be due to the increase of unbalanced forces due to variation of gas pressure inside the cylinder. In longitudinal direction also, peak amplitudes are observed to be lesser at no load condition as it is observed in vertical and lateral directions.

\section{Comparison of Engine Vibration in Three Mutually Perpendicular Directions}

Figure 15 shows super imposed time waves at full load for engine running with diesel and NME in vertical, longitudinal, and lateral directions. It is observed that vertical and longitudinal vibrations are higher compared to lateral vibration. From Figure 16, it is also observed that within the range of $0-100 \mathrm{~Hz}$, the engine peak vibration amplitudes are lesser in vertical direction compared to lateral and longitudinal directions at all multiple frequencies of $12.5 \mathrm{~Hz}$. However, the higher mechanical induced vibration is obtained along lateral and longitudinal directions at low frequencies. It may be due to more unbalanced forces along the lateral and longitudinal directions due to the motion of reciprocating and rotary components of engine. The effect of fuel is not significant at low frequencies as is shown in Figure 16. The change in vibration at maximum load is $1.26 \%$, $0.2 \%$, and $6.4 \%$ along vertical, lateral, and longitudinal directions when fuel is changed from diesel to NME. However, significant changes are observed in engine vibration in a high frequency zone at more than $100 \mathrm{~Hz}$. The change in vibration is $64.94 \%, 86.41 \%$, and $17 \%$ along vertical, lateral, and longitudinal directions when fuel is changed from NME to diesel. It may be due to the presence of combustion induced vibration at high frequency zones [9]. 


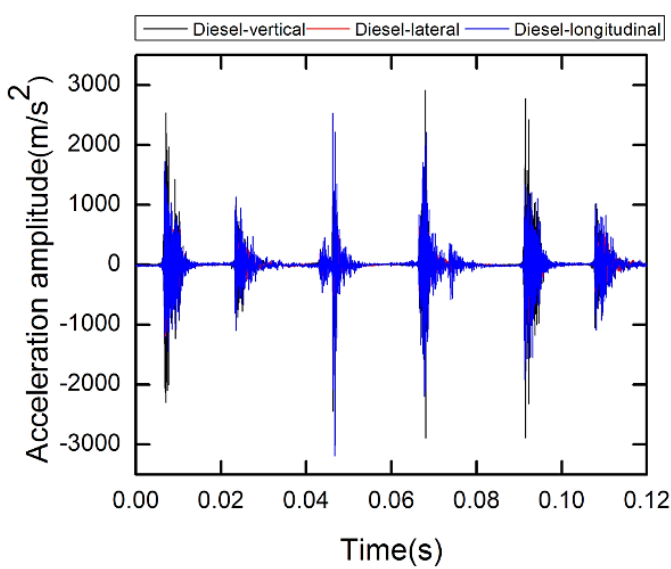

(a)

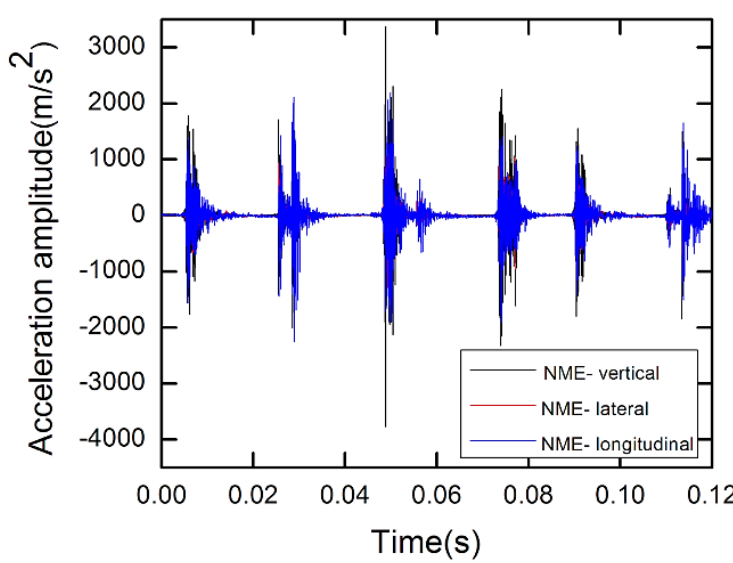

(b)

Figure 15. Time waves in vertical, lateral, and longitudinal directions at a maximum load of $12 \mathrm{~kg}$ for engine operated with (a) diesel (b) NME.

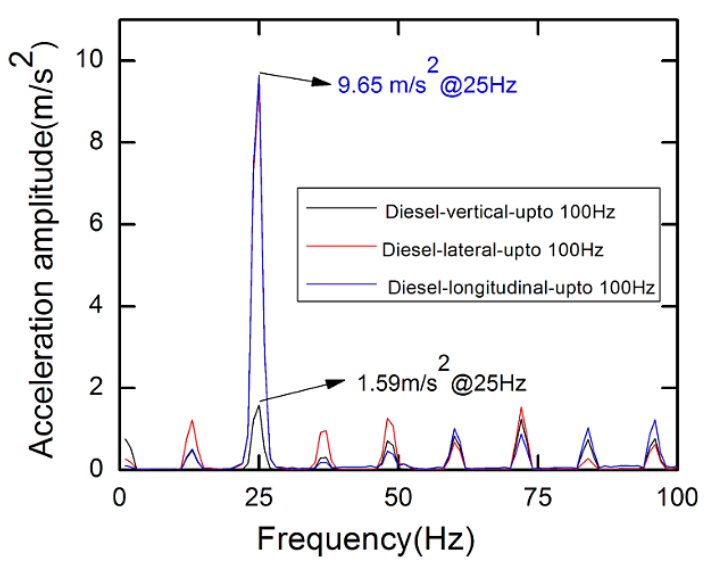

(a)

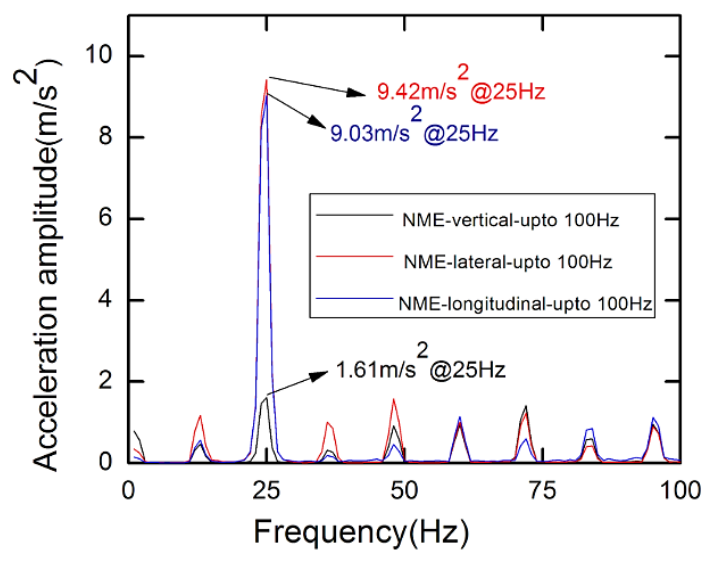

(b)

Figure 16. Frequency spectrums in vertical, lateral, and longitudinal directions at a maximum load of $12 \mathrm{~kg}$ for engine operated with (a) diesel (b) NME.

\section{CONCLUSIONS}

It is observed that the highest peak is obtained at the frequency of $25 \mathrm{~Hz}$ within the range of $0-100 \mathrm{~Hz}$, for engine running with both diesel and biodiesel. Moreover, higher vibrations are noticed along lateral and longitudinal directions compared to vertical direction. This may be due to higher mechanical induced vibration along lateral and longitudinal directions at low frequencies. It is noticed that, in longitudinal direction, the engine vibration is significantly affected with respect to load for both diesel and NME. The effect of fuel is not significant at low frequencies but considerable changes are observed in engine vibration at high frequencies. Within the range of $100-3000 \mathrm{~Hz}$, the highest peak amplitudes are observed for engine running with diesel compared to NME. It is concluded that high frequency vibrations are dominating for engine fuelled with diesel compared to NME.This may be due to the lower cetane number of diesel compared to NME. It is realized that combustion induced vibration is reduced when engine is operated with NME, in place of diesel. It is also noticed that more correlation is observed 
between the maximum rate of pressure rise and maximum peak vibration acceleration. As stringent emission norms are being implemented all over the world, it is suggested that biofuel can be used as a prominent fuel in diesel engines, in view of lesser emissions and vibrations.

\section{ACKNOWLEDGEMENTS}

The authors are grateful to UGC (University Grants Commission) and AICTE (All India Council For Technical Education), New Delhi, India, for funding this research work under MRPS (Grant no: MRP-4572/14(SERO/UGC), March 2014) and RPS (Grant no: 8023/RID/RPS/041/11/12 ) schemes.

\section{REFERENCES}

[1] Santana CM, Barros JEM, de Almeida HA. Analysis of vibration and noise of an internal combustion engine by application of test and experimental analysis of the frequency spectrum. SAE Technical Paper; 2013.

[2] Magaswaran K, Phuman Singh AS, Hassan MZ. A new method in the identification of noise and vibration characteristics of automotive disk brakes in the low frequency domain. International Journal of Automotive and Mechanical Engineering. 2014;9:1564-77.

[3] Mohanamurugan S, Sendilvelan S. Emission and combustion characteristics of different fuel In A HCCI engine. International Journal of Automotive and Mechanical Engineering. 2011;3:279-92.

[4] Selim MYE. Pressure-time characteristics in diesel engine fueled with natural gas. Renewable energy. 2001;22:473-89.

[5] Abou-Arab TW, Mohamed HS, Tayea DA. Thermo-mechanical (vibration \& noise) performance of CNG converted petrol engine. SAE Technical Paper; 2009.

[6] Hamada KI, Rahman MM. An experimental study for performance and emissions of a small four-stroke SI engine for modern motorcycle. International Journal of Automotive and Mechanical Engineering. 2014;10:1852-65.

[7] Wang C, Zhang Y, Zhong Z. Fault diagnosis for diesel valve trains based on timefrequency images. Mechanical Systems and Signal Processing. 2008;22:1981-93.

[8] Zhu J. Detection of cylinder pressure in diesel engines using cylinder head vibration and time series methods. Journal of Marine Science and Application. 2007;6:8-12.

[9] Taglialatela-Scafati F, Lavorgna M, Mancaruso E. Use of vibration signal for diagnosis and control of a four-cylinder diesel engine. SAE Technical Paper; 2011.

[10] Lujan J, Bermudez V, Guardiola C, Abbad A. A methodology for combustion detection in diesel engines through in-cylinder pressure derivate signal. Mechanical Systems and Signal Processing. 2010;24:2261-75.

[11] Bueno AV, Velásquez JA, Milanez LF. A new engine indicating measurement procedure for combustion heat release analysis. Applied Thermal Engineering. 2009;29:1657-75.

[12] Chiatti G, Chiavola O, Recco E. Combustion and vibration characteristics in a small displacement diesel engine fueled with biodiesel blends. SAE Technical Paper; 2013. 
[13] Chiatti G, Recco E, Chiavola O. Vibration processing to optimize pressure development in CR diesel engine. SAE Technical Paper; 2011.

[14] Polonowski C, Mathur V, Naber J, Blough J, Hpcr, E. SA. Accelerometer Based Sensing of Combustion in a High Speed Engine. Paper 0972. 2007:2007-01

[15] Carlucci A, Chiara F, Laforgia D. Analysis of the relation between injection parameter variation and block vibration of an internal combustion diesel engine. Journal of sound and vibration. 2006;295:141-64.

[16] Maurya RK, Pal DD, Agarwal AK. Digital signal processing of cylinder pressure data for combustion diagnostics of HCCI engine. Mechanical Systems and Signal Processing. 2013;36:95-109.

[17] Arasaratnam I, Habibi S, Kelly C, Fountaine TJ, Tjong J. Engine fault detection using vibration signal reconstruction in the crank-angle domain. SAE Technical Paper; 2011.

[18] Flekiewicz M, Fabi P, Flekiewicz B. Engine block vibration level as a tool for fuel recognition. SAE Technical Paper; 2007.

[19] Arnone L, Boni M, Manelli S, Chiavola O, Conforto S, Recco E. Diesel engine combustion monitoring through block vibration signal analysis. SAE Technical Paper; 2009.

[20] Helwani Z, Othman MR, Aziz N, Fernando WJN, Kim J. Technologies for production of biodiesel focusing on green catalytic techniques: a review. Fuel Processing Technology. 2009;90:1502-14.

[21] Yasin MHM, Mamat R, Aziz A, Yusop AF, Ali MH. Investigation on combustion parameters of palm biodiesel operating with a diesel engine. Journal of Mechanical Engineering and Sciences. 2015;9:1714-26.

[22] Canakci M, Erdil A, Arcaklioğlu E. Performance and exhaust emissions of a biodiesel engine. Applied energy. 2006;83:594-605.

[23] Senatore A, Cardone M, Rocco V, Prati MV. A comparative analysis of combustion process in DI diesel engine fueled with biodiesel and diesel fuel. SAE Technical Paper; 2000.

[24] ASTM, Standard Specification for Biodiesel Fuel (B100) Blend Stock for Distillate Fuels.

[25] Georgogianni K, Katsoulidis A, Pomonis P, Kontominas M. Transesterification of soybean frying oil to biodiesel using heterogeneous catalysts. Fuel Processing Technology. 2009;90:671-6.

[26] Chakraborty R, Bepari S, Banerjee A. Transesterification of soybean oil catalyzed by fly ash and egg shell derived solid catalysts. Chemical Engineering Journal. 2010;165:798-805.

[27] Thiruvengadaravi K, Nandagopal J, Baskaralingam P, Bala VSS, Sivanesan S. Acid-catalyzed esterification of karanja (Pongamia pinnata) oil with high free fatty acids for biodiesel production. Fuel. 2012;98:1-4.

[28] Abdul Adam A, Amir K, Bukhari M, Izzuddin Z. Performance and emissions characteristics of crude jatropha oil biodiesel blends in a diesel engine. International Journal of Automotive and Mechanical Engineering. 2015;11:244757.

[29] Azad AK, Ameer Uddin SM, Alam MM. a comprehensive study of DI diesel engine performance withvegetable oil: an alternative bio-fuel source of energy. International Journal of Automotive and Mechanical Engineering. 2012;5:576-86. 
[30] Qi D, Geng L, Chen H, Bian YZ, Liu J, Ren XC. Combustion and performance evaluation of a diesel engine fueled with biodiesel produced from soybean crude oil. Renewable Energy. 2009;34:2706-13.

[31] Canakci M. Combustion characteristics of a turbocharged DI compression ignition engine fueled with petroleum diesel fuels and biodiesel. Bioresource Technology. 2007;98:1167-75.

[32] Karavalakis G, Hilari D, Givalou L, Karonis D, Stournas S. Storage stability and ageing effect of biodiesel blends treated with different antioxidants. Energy. 2011;36:369-74.

[33] Chauhan BS, Kumar N, Cho HM. A study on the performance and emission of a diesel engine fueled with Jatropha biodiesel oil and its blends. Energy. 2012;37:616-22.

[34] Fukuda H, Kondo A, Tamalampudi S. Bioenergy: Sustainable fuels from biomass by yeast and fungal whole-cell biocatalysts. Biochemical Engineering Journal. 2009;44:2-12.

[35] Jaichandar S, Annamalai K. Jatropha oil methyl ester as diesel engine fuel-an experimental investigation. International Journal of Automotive and Mechanical Engineering. 2016;13.

[36] Hoque N, Mourshed M, Das B. Performance and emission comparison of Karanja (pongamia pinnata), Pithraj (aphanamixis polystachya), Neem (azadira chtaindica) and Mahua (madhuca longofolia) seed oil as a potential feedstock for biodiesel production in Bangladesh. International Journal of Automotive and Mechanical Engineering. 2015;12: 2967-82.

[37] Conshohocken PA. ASTM b. Standard specification for biodiesel fuel blend stock B100 for middle distillate fuels annual book of West. 2008:D6751-07.

[38] Pradeep V, Sharma R. Evaluation of performance, emission and combustion parameters of a fuelled with bio-diesel from rubber seed oil and its blends. SAE Technical Paper 2005-26-353, 2005.

[39] Demirbas A. Progress and recent trends in biodiesel fuels. Energy Convers Manage. 2009;50:14-34.

[40] Jain S, Sharma M. Application of thermogravimetric analysis for thermal stability of Jatropha curcas biodiesel. Fuel. 2012;93:252-7.

[41] Sahoo P, Das L, Babu M, Naik S. Biodiesel development from high acid value polanga seed oil and performance evaluation in a CI engine. Fuel. 2007;86:44854.

[42] Taghizadeh-Alisaraei A, Ghobadian B, Tavakoli-Hashjin T, Mohtasebi SS. Vibration analysis of a diesel engine using biodiesel and petrodiesel fuel blends. fuel. 2012;102:414-22.

[43] Barelli L, Bidini G, Buratti C, Mariani R. Diagnosis of internal combustion engine through vibration and acoustic pressure non-intrusive measurements. Applied Thermal Engineering. 2009;29:1707-13.

[44] Goldwine G, Rivin B, Sher E. Studying the relationship between the vibration signature and the combustion process in diesel engines. SAE Technical Paper; 2004.

[45] Chiatti G, Chiavola O, Recco E. Diesel combustion analysis via block vibration during engine transient operation. SAE Technical Paper; 2013.

[46] Schaberg P, Priede T, Dutkiewicz R. Effects of a rapid pressure rise on engine vibration and noise. SAE Technical Paper; 1990. 
[47] How H, Masjuki H, Kalam M, Teoh Y. An investigation of the engine performance, emissions and combustion characteristics of coconut biodiesel in a high-pressure common-rail diesel engine. Energy. 2014;69:749-59.

[48] Chiatti G, Chiavola O, Recco E, E. SA. Accelerometer Measurements to Optimize the Injection Strategy. Paper 1341. 2012:2012-01

[49] Cheng Y, Tang J, Ji S, Huang M. Combustion timing determination based on vibration velocity in HCCI engines. Mechanism and Machine Theory. 2012;58:20-8.

[50] Datta A, Palit S, Mandal BK. An experimental study on the performance and emission characteristics of a CI engine fuelled with Jatropha biodiesel and its blends with diesel. Journal of Mechanical Science and Technology. 2014;28:1961-6.

[51] Hasan M, Rahman M, Kadirgama K. A review on homogeneous charge compression ignition engine performance using biodiesel-diesel blend as a fuel. International Journal of Automotive and Mechanical Engineering. 2015;11:2199.

[52] Oo CW, Shioji M, Nakao S, Dung NN, Reksowardojo I, Roces SA, et al. Ignition and combustion characteristics of various biodiesel fuels (BDFs). Fuel. 2015;158:279-87.

\section{NOMENCLATURE}

$\begin{array}{ll}\text { RMS } & : \text { Root mean square } \\ \text { AI } & \text { : Analog input } \\ \text { NME } & : \text { Neem methyl ester } \\ \text { A/D } & : \text { Analog to digital } \\ \text { BTDC } & : \text { Before top dead centre } \\ \text { CI } & \text { : Compression ignition } \\ \text { STFT } & : \text { Short term fourier transform } \\ \text { VCR } & : \text { Variable compression ratio } \\ \text { AI } & : \text { Analog input } \\ \text { NI } & : \text { National Instruments } \\ \text { BNC } & : \text { Bayonet Neill- Concelman }\end{array}$

